\title{
The Behavioural Effects of Extreme Events in Global Supply Chains
}

\author{
John Tainton and Masaru Nakano \\ The Graduate School of System Design and Management, Keio University, \\ Kyosei Building, 4-1-1, Hiyoshi, Kohoku-ku, Yokohama, Kanagawa, 223-8526, Japan \\ jrtainton@gmail.com, nakano@sdm.keio.ac.jp
}

\begin{abstract}
Extreme events and disasters have always been part of our lives, however as the world has become increasingly globalized over the past few decades in an attempt to reduce production costs and access new markets, these events are more likely than ever to affect businesses. It is therefore important for business to understand how these events affect their supply chains. This paper identifies behavioural patterns of manufacturing supply chains under the effects of extreme events such as financial crises and big earthquakes. A simulation model is then used to expose the underlying structure of each behavioural pattern.
\end{abstract}

Keywords: Sustainable supply chain, Extreme events, Supply chain risk management, Disruption behavior, Automotive industry.

\section{Introduction}

There are many studies in the context of sustainable supply chain including green, competitive and resilient to risk but less in risk management than in green and competitive issues (Nakano [1]). In the past 10 years, the world has experienced many disasters that have directly affected businesses and their ability to deliver goods and services, as well as support their customers. A recent example of this can be seen in the Great East Japan Earthquake and Tsunami of 2011. Toyota Motor Corporation is estimated to have lost production of nearly 700,000 vehicles as a direct result of the earthquake. These events affect not only the direct area but also cause changes in locations distant from the disaster location. Sheffi [2], Norrman \& Jansson [3], and Tang [4] provide many alternative case studies for disruptions and risks in supply chains.

Business risks and their classifications have been provided by Nakano [5] and Goshal [6]. Nakano [5], and Manuj \& Mentzer [7] transferred these classifications of business risk to supply chains. However the globalization of supply chains has continued to increase and is currently at an all-time high. Due to the distances and complexities of operating in a global environment, the risks in global supply chains are more extreme according to Manuj \& Mentzer [8]. 


\section{Extreme Events}

Extreme events have historically been defined in a general sense and have included the terms: rare, severe, unpredictable, large social impact and retrospective predictability Bier [9], Taleb [10], and Casti [11]. In the context of global supply chains the authors define an extreme event as: An event that causes bankruptcy or long term ( $>1$ month) supply or demand disruption to a global supply chain.

Extreme events also have two phases of effects as shown in Fig. 1. "Primary effects" refers to the direct localized impact of a disaster. "Secondary effects" refers to the delayed effects that impact companies after an extreme event occurs.

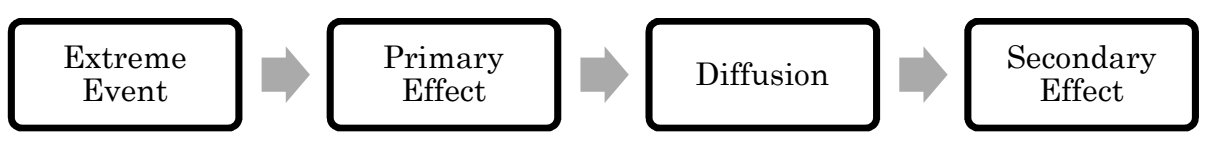

Fig. 1. Primary and secondary effects of an extreme event

Currently there is a lack of understanding on how and why different extreme events result in different behaviours in supply chains. It is critical for companies and countries to understand the differences in the behaviour of secondary effects of disasters in order to better prepare itself for disaster recovery and business continuity.

This paper aims to identify disruption behaviour types based on how the disaster affects in the supply chain.

\section{Behavioural Patterns}

Every extreme event is different as each event targets different weaknesses in the overall system to relieve the complexity gap. Therefore it is useful to study a variety of historical events, especially ones in recent history, where supply chains have begun to be more responsive.

The automotive sector of Japan was analysed between 2006 and 2012. Data was collected from JAMA [12]. During this period, two extreme events affected the supply chain significantly. The first event was the financial crisis of 2008 and the resulting global recession. The second event was the Great Tohoku Earthquake of 2011 which significantly affected the production capabilities of Japanese manufacturers with the M9.0 shake followed by big tsunamis and the nuclear reactor meltdown. Fig. 2 below shows the export levels of Japanese passenger vehicles between 2006 and 2012. In the graph above, we can see the 2 distinct supply disruptions and we can recognize that their behaviour patterns are different. A third pattern also emerged during the investigation. Fig. 3 below shows US airline passengers and how the 9/11 attacks affected the airline industry [13]. 


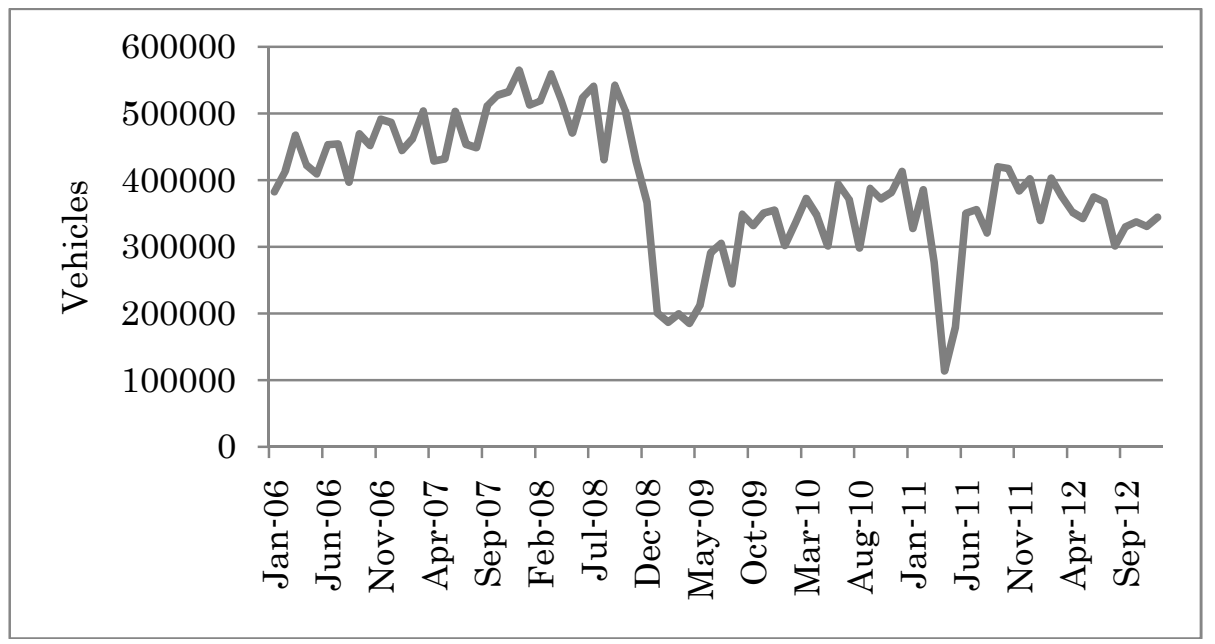

Fig. 2. Japanese Passenger Vehicle Exports

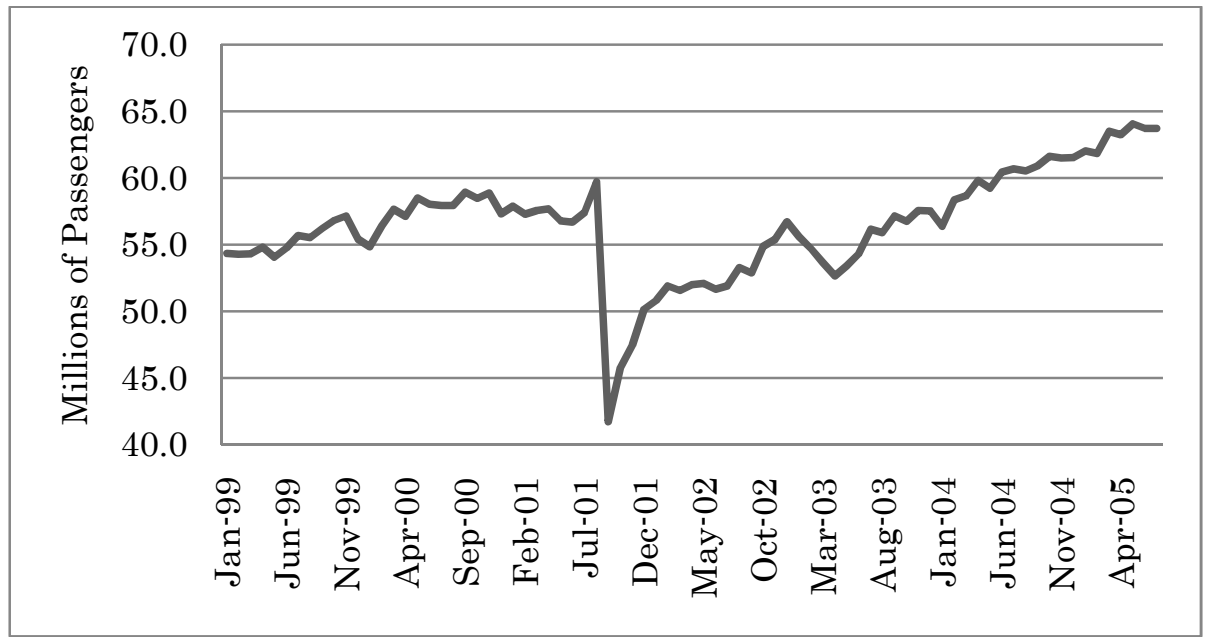

Fig. 3. De-Seasonalised US airline passengers

Three distinct disruptive event patterns have now been identified from the above cases.

- The first event type is based on the Great Tohoku Earthquake behaviour and is a supply disruption event. The disruptive pattern has a short impact period and a short recovery period making it look like a $\mathrm{V}$. This profile is therefore called the V-curve.

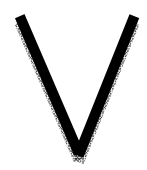


- The second event type is based on the Financial Crisis behaviour and is a demand disruption event. The disruptive pattern has a short impact period, but a slow, long recovery period making it look like a mirrored, slanted L. This profile is called the L-curve.

- The third event type is based on the 9/11 passenger behavior and is a mixed disruption event. The disruptive pattern has a short impact period, with two distinctive recovery periods. The initial recovery is sharp, similar to that of a V-curve, but during the recovery, the recovery speed changes to that of a $\mathrm{L}$ curve. This behavior pattern

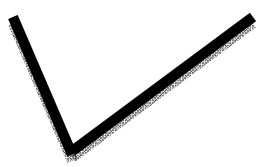
looks like a miss-shaped $\mathrm{W}$. This profile is called the Wcurve.

Suganuma and Nakano [14] analyzes the dominant effect of the Great Tohoku Earthquake on supply chains in Japanese automotive industry quantitatively by simulating using the inter-industry relations, the Input-Output Table [15]. The study, however, only explains a supply disruption without inventories. Therefore a simulation model is proposed next section to analyze the above three types of behaviors with inventories.

\section{$4 \quad$ A Simulation Model}

A simple simulation model of the export of vehicles from Japan to the United States was built to better understand the structure, mechanism and sequence of disruption events. The model follows the structure as shown in Fig. 4 below.

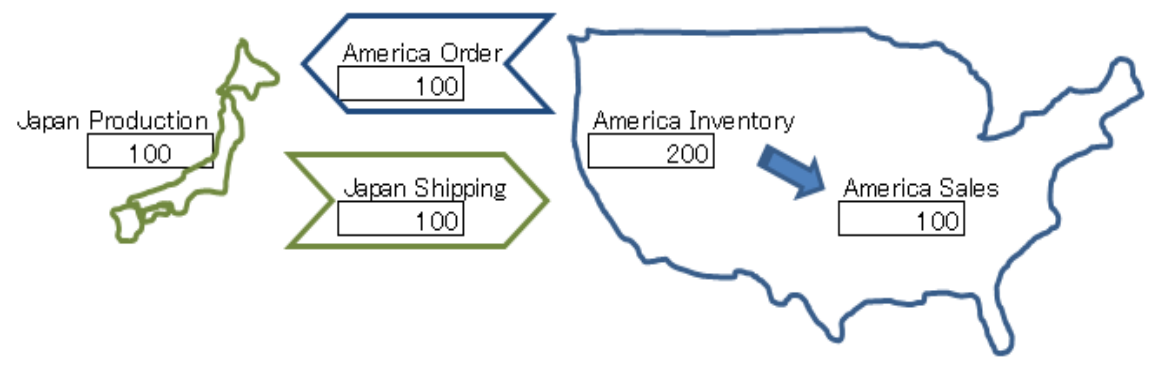

Fig. 4. Simulation Model Structure

The model contains 6 fields that change based on the previous month's data. The elements, descriptions and formulas are described in Table 1 below. 
Table 1. Simulation model elements and descriptions

\begin{tabular}{|c|c|c|}
\hline Field name & Description & Formula \\
\hline America Demand & $\begin{array}{l}\text { Demand for vehicles for } \\
\text { the month }\end{array}$ & Input \\
\hline America Sales & $\begin{array}{l}\text { Actual number of } \\
\text { vehicles sold }\end{array}$ & $\operatorname{Min}(\operatorname{Demand}(\mathrm{t})$, Inventory $(\mathrm{t}))$ \\
\hline $\begin{array}{l}\text { America } \\
\text { Inventory }\end{array}$ & $\begin{array}{l}\text { Number of vehicle } \\
\text { available to be sold }\end{array}$ & $\begin{array}{l}\text { Inventory }(\mathrm{t}-1)-\operatorname{Demand}(\mathrm{t}-1) \\
+\operatorname{Shipping}(\mathrm{t}-1)\end{array}$ \\
\hline $\begin{array}{l}\text { America Target } \\
\text { Inventory }\end{array}$ & $\begin{array}{l}\text { The desired number of } \\
\text { vehicles to keep as } \\
\text { inventory }\end{array}$ & $\begin{array}{c}\text { (Average (Demand }(\mathrm{t}-1, \mathrm{t}-2, \mathrm{t}- \\
3))) * 2\end{array}$ \\
\hline Japan Shipping & $\begin{array}{l}\text { Number of vehicles in } \\
\text { transit to America }\end{array}$ & $\operatorname{Order}(\mathrm{t}-1)$ \\
\hline America Order & $\begin{array}{l}\text { Orders placed by } \\
\text { America on Japan. }\end{array}$ & $\begin{array}{c}\text { Target Inventory }(\mathrm{t})- \\
\text { Inventory }(\mathrm{t})-\operatorname{Shipping}(\mathrm{t})+ \\
\text { Sales }(\mathrm{t}-1)+\text { Average }(\operatorname{Demand}(\mathrm{t}- \\
1, \mathrm{t}-2, \mathrm{t}-3))\end{array}$ \\
\hline
\end{tabular}

The model was calibrated using two variables: the total number of vehicles sold in the US and the number of vehicles imported from Japan using real data for 2008 and 2009. The percentage change in sales was used as the input variable and the output variable was the number of imported vehicles.

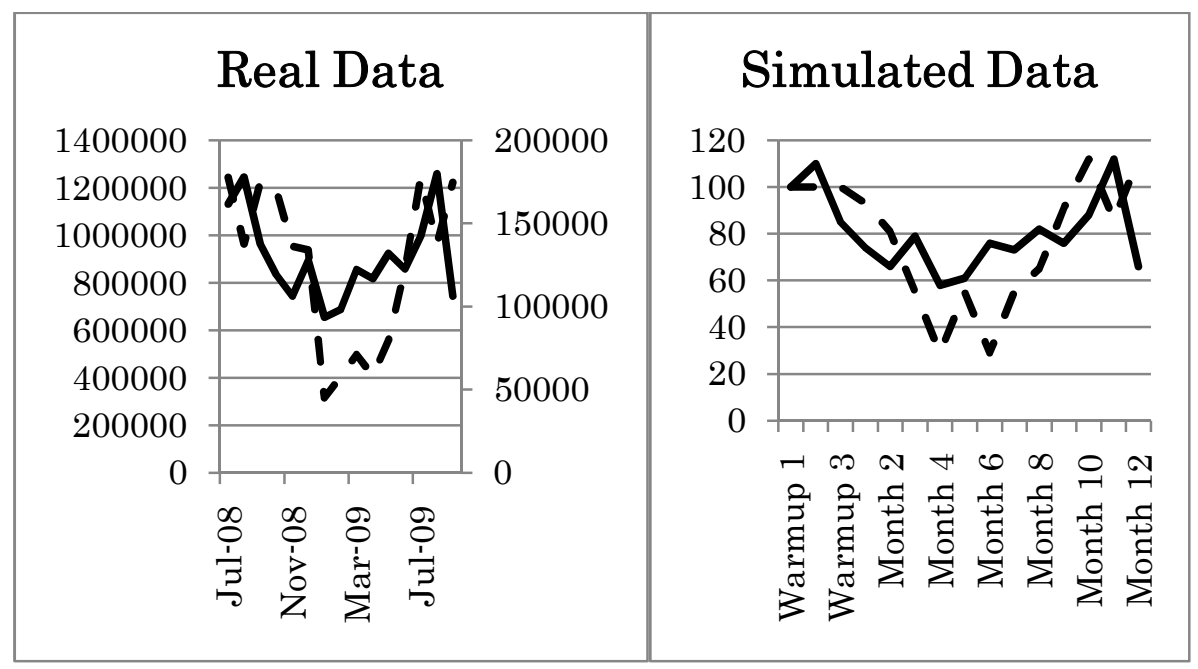

Fig. 5. \& 6. Model Calibration 
Legend for graphs below

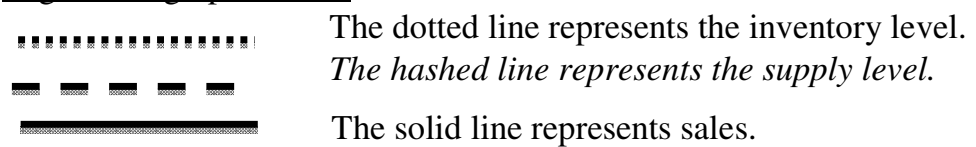

The figs. 5 and 6 below show the results of the model calibration.

The key behaviour of the two graphs is similar. The difference in behaviour is due to the number of import vehicle only making up roughly $10 \%$ of the total sales in the US. For the model, however, it accounts for $100 \%$ making the model very sensitive to change. The inventory is not verified due to lack of real data.

The model includes a variable that limits the amount of change in production from one month to another. This variable needed to be calibrated in order to achieve the best fit. The calibration made use of the RMSE (Root Mean Square Error) method to determine the best maximum change in production. The best fit was obtained by minimizing the RMSE. A maximum change of $27 \%$ is therefore the best fit for this model. The reason for the large percentage difference is due to the model assumption that total vehicle sales and imported vehicle sales have the same behaviour.

\section{$5 \quad$ Simulation Results}

Six case studies were then conducted: two for each of the three behaviour types. For the supply disruption scenario, the supply was changed in Month 1 from 100 to 20 according to the big earthquake in 2011. For the demand disruption scenario, the demand was changed in Month 1 from 100 to 80, 60, 60, 70, 80, 90, and 100 according to the real data in the financial crisis in 2008. The mixed disruption scenario combined the changes in the demand supply disruption scenarios.

The $1^{\text {st }}$ scenario has no limits, whereas the $2^{\text {nd }}$ scenario has a maximum change to production from month to month. The diffusion through the network for supply disruption is: Supply $->$ Inventory $->$ Sales. Figs. 7 and 8 show simulation results for supply disruption cases. The figures demonstrate the effect of the change limit. 


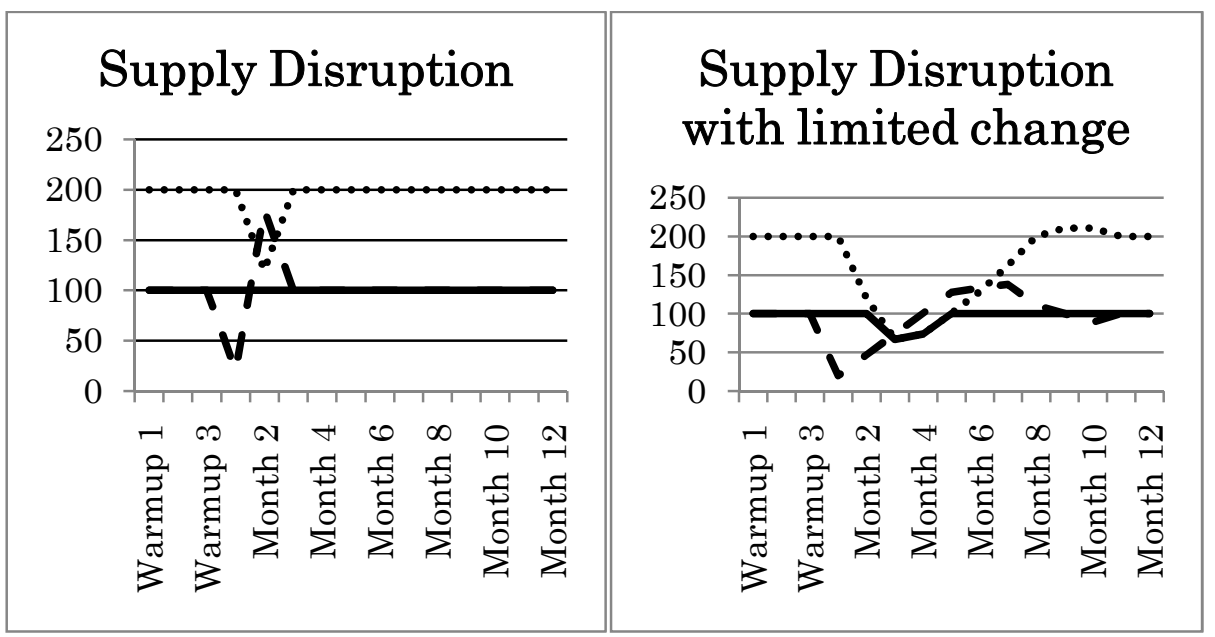

Fig. 7. \& 8. Supply disruption cases

For demand disruptions, a drop in demand is shown to cause a big drop in order volume to production due to the increase in inventory levels as shown in Figs. 9 and 10. The diffusion through the network is: Sales $->$ Inventory $->$ Supply.

Mixed disruption event behaviour is very similar to that of demand disruption behaviour; however the results are more extreme as shown in Figs. 11 and 12.

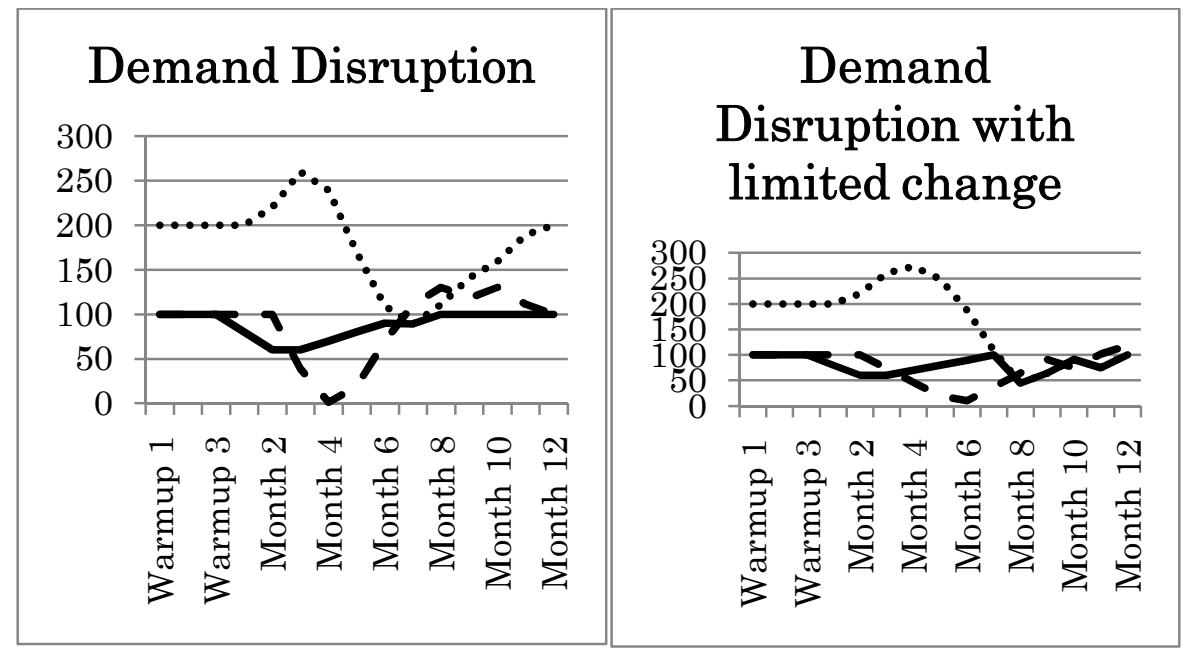

Figs. 9 \& 10. Demand disruption cases 


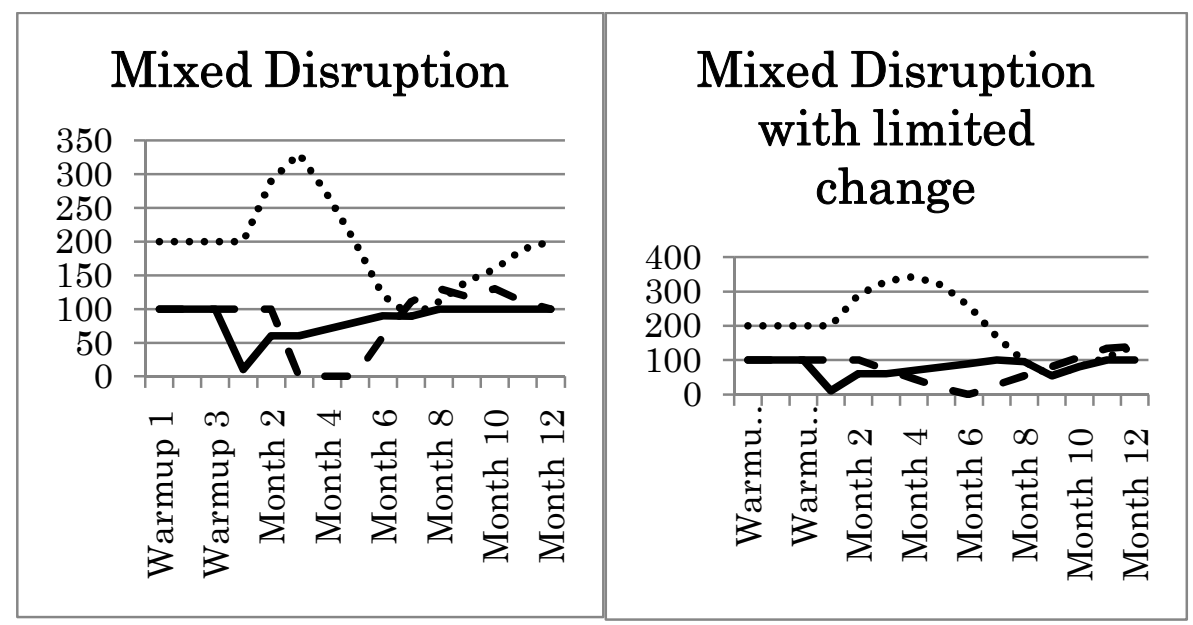

Figs. 11 \& 12. Mixed disruption cases

\section{Conclusion}

This paper analysed the behaviour of automotive supply chains in Japan from January 2006 until December 2012. Three behavioural types were identified: Demand Disruption, Supply Disruption and Mixed Disruption events. A simulation model was then constructed to analyse the underlying structure and behaviour of the supply chain under the disruption events. The limitation of supply change was a key to model the supply chain. Demand disruptions were found to have relatively short impact periods; however the recovery periods are significantly longer. Supply disruptions were found to have short impact periods as well as short recovery periods. A future work is to consider mitigation measures for manufacturers.

Acknowledgments. This work was enabled to the financial support of the Ministry of Education, Culture, Sports and Technology of Japan.

\section{References}

1. Nakano, M.: Supply Chain Management for Sustainability. In: Lee, K.M., Kauffman, J. (eds.) Handbook of Sustainable Engineering, pp. 427-450. Springer Science+Business Media, Dordrecht (2013)

2. Sheffi, Y.: The Resilient Enterprise: Overcoming Vulnerability for Competitive Advantage. MIT Press (2005)

3. Norrman, A., Jansson, U.: Ericsson's Proactive Supply Chain Risk Management Approach after a Serious Sub-Supplier Accident. International Journal of Physical Distribution \& Logistics Management 34(5), 434-456 (2004)

4. Tang, C.S.: Perspectives in Supply Chain Risk Management. International Journal of Production Economics 103(2), 451-488 (2006) 
5. Nakano, M.: A Conceptual Framework for Sustainable Manufacturing by Focusing on Risks in Supply Chains. In: Vallespir, B., Alix, T. (eds.) Advances in Production Management Systems. IFIP AICT, vol. 338, pp. 160-167. Springer, Heidelberg (2010)

6. Ghoshal, S.: Global Strategy: an Organizing Framework. Strategic Management Journal 8(5), 425-440 (1987)

7. Manuj, I., Mentzer, J.T.: Global Supply Chain Risk Management. Journal of Business Logistics 29(1), 133-155 (2008)

8. Manuj, I., Mentzer, J.T.: Global Supply Chain Risk Management Strategies. International Journal of Physical Distribution \& Logistics Management 38(3), 192-223 (2008)

9. Bier, V.M., Haimes, Y.Y., Lambert, J.H., Matalas, N.C., Zimmerman, R.: A Survey of Approaches for Assessing and Managing the Risk of Extremes. Risk Analysis 19(1), 83-94 (1999)

10. Taleb, N.N.: The Black Swan: The Impact of the Highly Improbable, pp. xxii. Random House Publishers (2007)

11. Casti, J.L.: X-Events: The Collapse of Everything. William Morrow Publishers (2012)

12. Japanese Automotive Manufacturers Association's Active Matrix Database System, http://jamaserv.jama.or.jp/newdb/eng/index.html (accessed on July 20, 2013) (in Japanese)

13. U.S. Department of Transportation, Research and Innovative Technology Administration, Bureau of Transportation Statistics (November 21, 2005)

14. Suganuma, S., Nakano, M.: Simulating the Dominant Effect of a Few Critical Sites on Supply Chains Using the Inter-industry Relations Table. In: Prabhu, V., Taisch, M., Kiritsis, D. (eds.) APMS 2013, Part I. IFIP AICT, vol.414, pp. 485-492. Springer, Heidelberg (2013)

15. Ministry of Economy, Trade and Industry of Japan, 2005. Inter-Regional Input-Output Tables (March 26, 2010) (in Japanese) 